\title{
Espacialização do intervalo hídrico ótimo de um Latossolo Vermelho em dois sistemas de colheita de cana-de-açúcar
}

\author{
Fernando Silva Araújo(1), Zigomar Menezes de Souza(2), Gustavo Soares de Souza(3), \\ Edson Eiji Matsura(2) e Ronny Sobreira Barbosa ${ }^{(2)}$
}

\begin{abstract}
(1)Universidade Estadual do Piauí, Avenida Joaquim Nogueira de Oliveira, s/no, CEP 64980-000 Corrente, PI, Brazil. E-mail: agronando16@hotmail.com (2)Universidade Estadual de Campinas, Faculdade de Engenharia Agrícola, Avenida Cândido Rondon, no 501, CEP 13083-875 Barão Geraldo, Campinas, SP. E-mail: zigomarms@feagri.unicamp.br, matsura@feagri.unicamp.br, rsbagronomo@hotmail.com ${ }^{(3)}$ Instituto Capixaba de Pesquisa, Assistência Técnica e Extensão Rural, Estação Experimental de Linhares, Caixa Postal 62, CEP 29915-140 Linhares, ES. E-mail: gustavo.souza@incaper.es.gov.br
\end{abstract}

\begin{abstract}
Resumo - O objetivo deste trabalho foi avaliar o intervalo hídrico ótimo de um Latossolo Vermelho sob cultura de cana-de-açúcar com colheita mecanizada ou manual, e determinar a relação de dependência espacial deste atributo com a produtividade da cultura. $\mathrm{O}$ trabalho foi desenvolvido em duas áreas cultivadas com cana-de-açúcar, uma colhida mecanicamente sem queima desde 1996, e outra colhida com corte manual e queima desde 1973. O intervalo hídrico ótimo foi avaliado pela mensuração da resistência do solo à penetração e pela determinação da água no solo a 0,002, 0,006, 0,01,0,03, 0,05, 0,1,0,5 e 1,5 MPa. O intervalo hídrico ótimo variou com as alterações ocorridas no solo, nos dois sistemas de manejo estudados, o que indica maior degradação estrutural do solo e menor conteúdo de água disponível na área com colheita manual. A maior produtividade da cultura se concentra nas regiões de maior intervalo hídrico ótimo.
\end{abstract}

Termos para indexação: compactação do solo, resistência do solo à penetração, variabilidade espacial.

\section{Spatialization of least limiting water range in an Oxisol under two sugarcane harvesting systems}

\begin{abstract}
The objective of this work was to evaluate the least limiting water range of an Oxisol under a sugarcane cultivation with mechanical and manual harvesting, and to establish the spatial variability relationship between this attribute and crop productivity. The work was conducted in two areas cultivated with sugarcane, one of which was mechanically harvested without burning since 1996, and the other was manually harvested after burning since 1973. The least limiting water range was evaluated by determining the soil resistance to penetration at $0.002,0.006,0.01,0.03,0.05,0.1,0.5$ and $1.5 \mathrm{MPa}$ soil-water potentials. The least limiting water range varied with soil management changes in both studied systems, which indicates a greater soil degradation and lower water content in the area under manual harvesting. The greater crop yield concentrates in regions of higher least limiting water range.
\end{abstract}

Index terms: soil compaction, soil-penetration resistance, spatial variability.

\section{Introdução}

Com o uso crescente de fontes de energia renováveis, novas tecnologias têm sido incorporadas, para maximizar a produção da cana-de-açúcar brasileira. Uma alternativa para o setor sucroalcooleiro é a mecanização da colheita da cana-de-açúcar, sem a queima prévia do canavial (cana crua), aliada à adoção da agricultura de precisão (Souza et al., 2012), para permitir a otimização do uso de insumos agrícolas, redução de custos da lavoura e o aumento da produtividade.

Com a adoção da colheita mecanizada, no sistema de manejo da cana-de-açúcar, surge a preocupação com a compactação do solo e seus efeitos sobre os atributos físicos do solo. A desestruturação física do solo afeta sua qualidade química e biológica, com reflexos na produtividade da cultura e nos aspectos ambientais da produção (Dexter, 2004; Pacheco \& Cantalice, 2011; Vasconcelos et al., 2012). A compactação caracterizase pela redução da porosidade total, em resposta ao pequeno aumento da microporosidade, redução acentuada dos poros de maior diâmetro e mudanças na continuidade e distribuição de poros (Souza et al., 2005). Como consequência, a densidade do solo e a resistência do solo à penetração aumentam e prejudicam a dinâmica da água, de nutrientes e o crescimento das raízes (Letey, 1985). 
$\mathrm{Na}$ tentativa de integrar e simplificar o monitoramento da qualidade física do solo, o intervalo hídrico ótimo (IHO) vem sendo utilizado como indicador da qualidade estrutural do solo. Em áreas sob cultivo de cana-de-açúcar, Roque et al. (2011) utilizaram o IHO para detectar alterações do conteúdo de água disponível às plantas promovido por diferentes sistemas de colheita. Betioli Junior et al. (2012) avaliaram a qualidade física de um Latossolo Vermelho distroférrico muito argiloso, com histórico de trinta anos sob plantio direto, que denotava a sensibilidade deste atributo como indicador de qualidade estrutural do solo.

A amplitude do IHO indica o risco de exposição das culturas ao estresse físico do solo e a magnitude em que a condição estrutural restringe o crescimento e desenvolvimento das plantas (Silva et al., 1994). Solos com estrutura preservada apresentam restrições apenas quanto ao deficit hídrico. Entretanto, quando a compactação atinge níveis excessivos, a aeração se torna deficiente sob condições de elevados conteúdos de água, e a resistência do solo à penetração pode restringir o crescimento das plantas com o ressecamento do solo (Lapen et al., 2004).

O objetivo deste trabalho foi avaliar o intervalo hídrico ótimo de um Latossolo Vermelho, sob a cultura de cana-de-açúcar com colheita mecanizada ou manual, e determinar uma relação entre a dependência espacial deste atributo e a produtividade da cultura.

\section{Material e Métodos}

O experimento foi realizado na Usina São Martinho, Município de Pradópolis, SP, a $21^{\circ} 18^{\prime} 67^{\prime \prime S}$, $48^{\circ} 11^{\prime} 38^{\prime \prime} \mathrm{W}$, e a $630 \mathrm{~m}$ de altitude. O clima da região, segundo a classificação de Köppen, é do tipo Cwa, mesotérmico de inverno seco, com precipitação média anual de $1.400 \mathrm{~mm}$, e chuvas concentradas no período de novembro a fevereiro; a temperatura média anual é de $16,1^{\circ} \mathrm{C}$, com temperatura no mês mais quente superior a $19^{\circ} \mathrm{C}$ e a do mais frio inferior a $12^{\circ} \mathrm{C}$ (Centro de Pesquisas Meteorológicas e Climáticas Aplicadas à Agricultura, 2013). O solo foi classificado como Latossolo Vermelho distrófico típico, com horizonte A moderado e relevo suave-ondulado, com declividade de 3 a 5\% (Santos et al., 2006).

As amostras de solo foram coletadas de duas áreas cultivadas com a cultivar RB855453 de cana-de-açúcar
(Saccharum sp.), com dois sistemas de colheita: colheita sem queima e corte mecanizado, desde 1996 (com 16 anos de implantação do sistema de cana crua); e colheita com queima e corte manual, desde 1973 (cana queimada). As áreas foram reformadas em agosto de 2007, ocasião em que se realizou a eliminação mecânica da soqueira da lavoura anteriormente instalada e a subsolagem à profundidade de $0,45 \mathrm{~m}$, apenas nos sulcos de plantio, com subsolador Asa Lazer de cinco hastes, espaçadas $40 \mathrm{~cm}$ umas das outras, com ponteiras do tipo "botinhas" (Stara, Não-Me-Toque, RS), seguido de gradagem com grade aradora (28 discos com diâmetro de 28"). O manejo da adubação seguiu as recomendações para a cultura, e foram aplicados $2,5 \mathrm{Mg} \mathrm{ha}^{-1}$ de calcário dolomítico, antes do revolvimento do solo com grade aradora, e $20 \mathrm{Mg} \mathrm{ha}^{-1}$ de torta de filtro, antes do plantio. Em julho de 2009 , após a colheita, 280 e $260 \mathrm{~kg} \mathrm{ha}^{-1}$ do formulado 32-00-02 foram aplicados, além de $100 \mathrm{~m}^{3} \mathrm{ha}^{-1} \mathrm{de}$ vinhaça.

Nas operações mecanizadas, foi usado um trator Case MX-270 (Case IH, Ponta Grossa, PR), com tração $4 \times 4$, com potência máxima do motor de $270 \mathrm{cv}$ (198 $\mathrm{kW}$ ), massa de 11,7 Mg e pneus traseiros 650-85 R38 e dianteiros 600-70 R30, com pressão de inflação de 110 e $150 \mathrm{kPa}$, respectivamente, para tracionar os implementos. Na colheita, realizada em junho de 2010, foi usada a colhedora de esteira Case A-7700, com potência máxima do motor de $335 \mathrm{cv}(246 \mathrm{~kW})$ e massa de $18,5 \mathrm{Mg}$, e o trator Case MX-270, que arrastava um transbordo de três compartimentos, com massa total média de $40 \mathrm{Mg}$ e pneus 600-50 R22,5, com pressão de inflação de $110 \mathrm{kPa}$.

A amostragem das áreas foi realizada em agosto de 2009, e foram coletadas amostras indeformadas para as determinações de porosidade do solo (total, macro e microporosidade), densidade do solo e determinação do intervalo hídrico ótimo. Estas amostras foram coletadas às profundidades de $0,00-0,10,0,10-0,20 \mathrm{e}$ 0,20-0,30 m. A área de estudo tinha 1,21 ha, e foram coletadas 121 amostras dos pontos de cruzamento de uma malha regular espaçados de $10 \mathrm{em} 10 \mathrm{~m}$.

Para a porosidade do solo, densidade do solo e produtividade da cultura da cana-de-açúcar, a amostragem foi realizada nos pontos de cruzamento de uma malha, com intervalos regulares de $10 \mathrm{~m}$, nas duas áreas com 1,21 ha, no total de 121 pontos por área. Em cada ponto desta malha foi levantada a sua cota, 
com o auxílio de uma estação total, e os pontos foram georreferenciados com um DGPS HiPer, (Topcon, Livermore, CA, USA) com precisão horizontal e vertical, respectivamente, de 3 e $5 \mathrm{~mm}$. Para a retirada das amostras, foram abertas trincheiras, espaçadas a $0,20 \mathrm{~m}$ da soqueira, com $0,50 \mathrm{~m}$ de profundidade, $0,40 \mathrm{~m}$ de largura e $0,60 \mathrm{~m}$ de comprimento. A produtividade da cana-de-açúcar foi determinada, nas duas áreas de estudo, tendo-se amostrado 2,0 m lineares na linha de plantio adjacente ao centro do ponto de cruzamento da malha amostral (121 pontos em cada área), e a produtividade apresentada nas duas áreas é a da segunda colheita (primeira soca).

Para a determinação da porosidade do solo, foram coletadas amostras indeformadas, com anéis volumétricos de $50 \mathrm{~mm}$ de altura e $50 \mathrm{~mm}$ de diâmetro, e a microporosidade foi determinada em mesa de tensão (Donagema et al., 2011). A porosidade total do solo foi obtida conforme Donagema et al. (2011), e a macroporosidade foi obtida por diferença entre a porosidade total e a microporosidade.

Para determinar o intervalo hídrico ótimo (IHO), utilizou-se o método descrito por Silva et al. (1994) e Tormena et al. (1998). Foram obtidos os seguintes dados: porosidade de aeração (PA) mínima de $0,10 \mathrm{~m}^{3} \mathrm{~m}^{-3}$, pela subtração de $0,10 \mathrm{~m}^{3} \mathrm{~m}^{-3}$ da porosidade total; umidade do solo, no ponto de murcha permanente (PMP) à tensão de $1,5 \mathrm{MPa}$; umidade do solo à capacidade de campo (CC), à tensão de 0,006 MPa; e a umidade do solo para cada densidade do solo em que se atinge o valor de resistência à penetração (RP) de 2,0 $\mathrm{MPa}$, considerando-se as plantas como fator limitante. A PA, a CC e o PMP tiveram seus valores linearizados de acordo com a densidade do solo.

A resistência do solo à penetração (RP) foi determinada em laboratório, nas amostras coletadas com os cilindros volumétricos, tendo-se utilizado um penetrômetro eletrônico MA-933 (Marconi, Piracicaba, SP) com velocidade constante de $0,0005 \mathrm{~mm} \mathrm{~s}^{-1}$, equipado com uma célula de carga de $200 \mathrm{~N}$, haste com cone de $0,003 \mathrm{~m}$ de diâmetro de base e semiângulo de $30^{\circ}$, receptor e interface acoplados a um microcomputador, para registro das leituras por meio de um programa próprio do equipamento. As determinações foram realizadas em amostras indeformadas, submetidas a diferentes tensões de água no solo $(0 ; 0,006 ; 0,01 ; 0,033 ; 0,05 ; 0,1 ; 0,2$ e 1,5 MPa). Para cada amostra, foram obtidos 96 valores, tendo-se eliminado os iniciais e finais e considerado apenas os $0,03 \mathrm{~m}$ centrais do cilindro de $0,05 \mathrm{~m}$.

Os atributos físicos do solo foram avaliados por meio de análise descritiva, tendo-se calculado a média, a mediana, variância, os valores máximos e mínimos, o coeficiente de variação, o coeficiente de assimetria e o coeficiente de curtose. A hipótese de normalidade dos dados foi verificada pelo teste de Kolmogorov-Smirnov, por meio do programa SAS Versão 9.2. (SAS Institute, Cary, NC, EUA). A dependência espacial da produtividade da cultura, a densidade do solo e o intervalo hídrico ótimo foram analisados por meio de ajustes de semivariogramas (Vieira, 2000), com base na pressuposição de estacionariedade da hipótese intrínseca estimada por:

$$
\hat{\gamma}(h)=\frac{1}{2 N(h)} \sum_{i=1}^{N(h)}\left[Z\left(x_{i}\right)-Z\left(x_{i}+h\right)\right]^{2},
$$

em que: $\mathrm{N}$ (h) é o número de pares experimentais de observações; e $\mathrm{Z}\left(\mathrm{x}_{\mathrm{i}}\right)$ e $\mathrm{Z}\left(\mathrm{x}_{\mathrm{i}}+\mathrm{h}\right)$ são separados por uma distância h. O semivariograma é representado pelo gráfico $\hat{\gamma}(\mathrm{h})$, versus $\mathrm{h}$. Do ajuste de um modelo matemático aos valores calculados de $\hat{\gamma}(\mathrm{h})$ são estimados os seguintes coeficientes do modelo teórico para o semivariograma: o efeito pepita, $\mathrm{C}_{0}$; o patamar, $\mathrm{C}_{0}+\mathrm{C}_{1}$; e o alcance, a.

O mapa temático do conteúdo de água disponível foi obtido pelo cruzamento dos dados de densidade das áreas com os modelos de estimativa do IHO; os valores de resistência à penetração $\left(\theta_{\mathrm{RP}}\right)$, capacidade de campo $\left(\theta_{\mathrm{CC}}\right)$ e ponto de murcha permanente $\left(\theta_{\mathrm{PMP}}\right)$ foram linearizados de acordo com a densidade do solo $\left(D_{S}\right)$, tendo-se utilizado a transformação logarítmica (Silva et al., 1994; Tormena et al., 1998). Os limites superiores do IHO foram $\theta_{\mathrm{CC}}$ e porosidade de aeração $\left(\theta_{\mathrm{PA}}\right)$, enquanto os limites inferiores foram $\theta_{\mathrm{PMP}}$ e $\theta_{\mathrm{RP}}$, e o conteúdo de água disponível foi obtido pela diferença do teor de água $\left(\mathrm{m}^{3} \mathrm{~m}^{-3}\right)$ entre os limites superior e inferior do IHO.

\section{Resultados e Discussão}

$\mathrm{Na}$ área submetida à colheita mecanizada, os valores da média e mediana, para todas as variáveis, estão próximos, o que mostra distribuições simétricas, confirmadas pelos valores de assimetria próximos de zero (Tabela 1). Os resultados do teste de normalidade

Pesq. agropec. bras., Brasília, v.48, n.6, p.651-660, jun. 2013 DOI: 10.1590/S0100-204X2013000600011 
de Kolmogorov-Smirnov indicaram normalidade para todas as variáveis à profundidade de $0,00-0,10 \mathrm{~m}$. Souza et al. (2009) avaliaram a variabilidade espacial de atributos físicos do solo, em diferentes formas do relevo sob cultivo de cana-de-açúcar, e encontraram normalidade para a densidade e a porosidade do solo. A classificação para o coeficiente de variação (CV) proposta por Warrick \& Nielsen (1980) foi adotada para todas as profundidades estudadas, com exceção da macroporosidade que apresentou valores altos ( $>24 \%)$; os atributos de solo estudados apresentaram valores de CV baixos $(<12 \%)$ em todas as profundidades (Tabela 1). Estes resultados corroboram os obtidos por Souza et al. (2009) que, ao avaliar a dependência espacial de atributos físicos do solo, em áreas sob cultivo de cana-de-açúcar, encontraram valores elevados de $\mathrm{CV}$ quanto à macroporosidade.

Em estudo sobre a dependência espacial de atributos de solo, em áreas sob colheita mecanizada de cana-de-açucar, Berner et al. (2007) afirmaram que o cultivo contínuo aumenta a estabilidade da variabilidade espacial de atributos relacionados à porosidade do solo.

Tabela 1. Estatísticas descritivas da porosidade e da densidade de um Latossolo Vermelho distrófico, com 14 anos de colheita mecanizada e com 20 anos de colheita manual da cana-de-açúcar, às profundidades 0,00-0,10 m, 0,10-0,20 m e 0,20-0,30 m.

\begin{tabular}{|c|c|c|c|c|c|c|c|c|}
\hline \multirow[t]{3}{*}{ Estatística } & \multicolumn{4}{|c|}{ Colheita mecanizada } & \multicolumn{4}{|c|}{ Colheita manual } \\
\hline & \multicolumn{3}{|c|}{ Porosidade $\left(\mathrm{m}^{3} \mathrm{~m}^{-3}\right)$} & \multirow{2}{*}{$\begin{array}{c}\text { Densidade } \\
\left(\mathrm{Mg} \mathrm{m}^{-3}\right)\end{array}$} & \multicolumn{3}{|c|}{ Porosidade $\left(\mathrm{m}^{3} \mathrm{~m}^{-3}\right)$} & \multirow{2}{*}{$\begin{array}{c}\text { Densidade } \\
\left(\mathrm{Mg} \mathrm{m}^{-3}\right)\end{array}$} \\
\hline & Total & Macro & Micro & & Total & Macro & Micro & \\
\hline & \multicolumn{8}{|c|}{$0,00-0,10 \mathrm{~m}$} \\
\hline Média & 0,570 & 0,098 & 0,472 & 1,2 & 0,583 & 0,094 & 0,462 & 1,33 \\
\hline Mediana & 0,565 & 0,088 & 0,470 & 1,2 & 0,580 & 0,115 & 0,466 & 1,34 \\
\hline Mínimo & 0,462 & 0,001 & 0,370 & 1,0 & 0,377 & 0,030 & 0,239 & 1,09 \\
\hline Máximo & 0,683 & 0,276 & 0,632 & 1,5 & 0,727 & 0,256 & 0,663 & 1,55 \\
\hline DP & 0,037 & 0,067 & 0,055 & 0,114 & 0,039 & 0,053 & 0,046 & 0,099 \\
\hline CV (\%) & 6,62 & 68,37 & 11,67 & 9,35 & 6,85 & 44,27 & 10,03 & 7,43 \\
\hline $\mathrm{Cs}$ & 0,38 & 0,53 & 0,27 & 0,42 & $-0,254$ & 0,658 & $-0,550$ & $-0,112$ \\
\hline $\mathrm{Ck}$ & 0,23 & $-0,46$ & $-0,43$ & $-0,01$ & 6,975 & $-1,190$ & 6,133 & $-0,373$ \\
\hline$\overline{p^{1}}$ & $0,074^{\mathrm{ns}}$ & $0,073^{\mathrm{ns}}$ & $0,058^{\mathrm{ns}}$ & $0,21^{\mathrm{ns}}$ & $0,092 *$ & $0,089 *$ & $0,094^{*}$ & $0,063^{\mathrm{ns}}$ \\
\hline \multirow[t]{2}{*}{$\mathrm{p}^{2}$} & $0,0166^{* *}$ & $0,004^{*}$ & $0,1239^{\mathrm{ns}}$ & $0,0001 *$ & & & & \\
\hline & \multicolumn{8}{|c|}{$0,10-0,20 \mathrm{~m}$} \\
\hline Média & 0,549 & 0,079 & 0,470 & 1,3 & 0,556 & 0,098 & 0,458 & 1,41 \\
\hline Mediana & 0,549 & 0,075 & 0,461 & 1,3 & 0,556 & 0,093 & 0,465 & 1,41 \\
\hline Mínimo & 0,489 & 0,007 & 0,379 & 1,0 & 0,455 & 0,020 & 0,255 & 1,07 \\
\hline Máximo & 0,617 & 0,193 & 0,606 & 1,5 & 0,685 & 0,356 & 0,541 & 1,73 \\
\hline DP & 0,029 & 0,043 & 0,042 & 0,114 & 0,030 & 0,048 & 0,041 & 0,957 \\
\hline CV $(\%)$ & 5,38 & 54,77 & 8,96 & 9,02 & 5,38 & 48,59 & 9,07 & 6,79 \\
\hline $\mathrm{Cs}$ & 0,084 & 0,332 & 0,543 & $-0,034$ & 0,071 & 1,919 & $-2,483$ & $-0,143$ \\
\hline $\mathrm{Ck}$ & $-0,6960$ & $-0,529$ & 0,332 & $-0,412$ & 4,203 & 7,547 & 9,015 & 1,210 \\
\hline$\overline{\mathrm{P}^{1}}$ & $0,051^{\mathrm{ns}}$ & $0,068^{\mathrm{ns}}$ & $0,097^{*}$ & $0,181 *$ & $0,087 * *$ & $0,100 *$ & $0,138 *$ & $0,079^{\text {ns }}$ \\
\hline \multirow[t]{2}{*}{$\mathrm{p}^{2}$} & $0.098^{\mathrm{ns}}$ & $0,0022 *$ & $0,022 * *$ & $0,0001^{*}$ & & & & \\
\hline & \multicolumn{8}{|c|}{$0,20-0,30 \mathrm{~m}$} \\
\hline Média & 0,534 & 0,065 & 0,468 & 1,3 & 0,562 & 0,095 & 0,467 & 1,38 \\
\hline Mediana & 0,529 & 0,063 & 0,457 & 1,3 & 0,558 & 0,091 & 0,466 & 1,39 \\
\hline Mínimo & 0,447 & 0,001 & 0,369 & 1,0 & 0,456 & 0,019 & 0,371 & 1,11 \\
\hline Máximo & 0,657 & 0,163 & 0,628 & 1,6 & 0,759 & 0,214 & 0,678 & 1,60 \\
\hline DP & 0,030 & 0,037 & 0,042 & 0,1 & 0,036 & 0,038 & 0,085 & 0,085 \\
\hline CV (\%) & 5,70 & 57,03 & 9,08 & 7,86 & 6,49 & 40,09 & 7,92 & 6,17 \\
\hline $\mathrm{Cs}$ & 1,086 & 0,559 & 0,792 & $-0,189$ & 1,694 & 0,804 & 2,477 & 0,085 \\
\hline $\mathrm{Ck}$ & 3,0 & $-0,04$ & 1,052 & 0,413 & 8,164 & 1,065 & 13,459 & 0,534 \\
\hline$\overline{p^{1}}$ & $0,10^{*}$ & $0,078 \mathrm{~ns}$ & $0,11 *$ & $0,227^{*}$ & $0,138^{*}$ & $0,084 * *$ & $0,138^{*}$ & $0,080 * *$ \\
\hline $\mathrm{p}^{2}$ & $0,0001 *$ & $0,0001 *$ & $0,752^{\mathrm{ns}}$ & $0,0001 *$ & & & & \\
\hline
\end{tabular}

DP, desvio-padrão; CV, coeficiente de variação; CS, assimetria; CK, curtose; p $^{1}$, estatística do teste Kolmogorov-Smirnov (teste da normalidade dos dados);

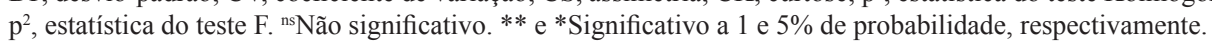


Os valores da porosidade total e da macroporosidade do solo sob colheita mecanizada foram inferiores $(p<0,01)$, em todas as camadas estudadas, em comparação ao manejo com corte manual da cana, exceto na camada de 0,10 a $0,20 \mathrm{~m}$, em que não houve diferença estatística quanto à porosidade total (Tabela 1). A maior densidade do solo, nas profundidades estudadas, não se refletiu em menor macroporosidade, nem em aumento da microporosidade na área com queima do canavial, o que contraria os dados de Souza et al. (2005).

A área com queima do canavial apresentou maiores valores médios de macroporosidade nas camadas de 0,10-0,20 e 0,20-0,30 m, em comparação à área com colheita mecanizada, e não houve diferença significativa $(p<0,01)$, entre os sistemas de colheita, quanto à microporosidade em todas as profundidades estudadas, exceto na camada de 0 a $0,10 \mathrm{~m}$, em que a área com queima do canavial apresentou maiores valores de microporosidade. Em um Latossolo Vermelho distrófico, sob diferentes sistemas de colheita da cana-de-açúcar, Garbiate et al. (2011) encontraram resultados semelhantes para macro e microporosidade.

A área com colheita manual apresentou os maiores valores de densidade do solo, em comparação à área com colheita mecanizada $(\mathrm{p}<0,01)$. Tal fato pode estar associado à manutenção dos resíduos vegetais na área com colheita mecanizada, sem a queima prévia do canavial. Em estudo sobre o efeito de resíduos vegetais na superfície e o carbono orgânico do solo e suas relações com a densidade máxima obtida no ensaio de Proctor, Braida et al. (2006) afirmaram que resíduos vegetais deixados à superfície do solo são capazes de absorver parte da energia de compactação produzida pelo trânsito de máquinas. Tal observação corrobora a relatada por Garbiate et al. (2011), que encontraram menores valores de densidade em áreas de cana-de-açúcar, sob colheita mecanizada, sem queima prévia do canavial, em comparação a sistemas de colheita com queima prévia do canavial.

Os modelos ajustados para a estimativa da resistência do solo à penetração explicaram 55,48 e 61,3\% da variabilidade dos dados das áreas com colheita mecanizada e colheita manual, respectivamente (Tabela 2). Os coeficientes do modelo apresentados mostram que a resistência variou positivamente com a densidade do solo e negativamente com o conteúdo de água, o que corrobora os resultados obtidos por outros autores (Freddi et al., 2009; Roque et al., 2011; Lima et al., 2012).

As estimativas dos conteúdos de água do solo, pelos modelos ajustados, explicaram 77,51 e 83,77\% da variabilidade dos dados das áreas com colheita mecanizada e colheita manual, respectivamente (Tabela 2). Os coeficientes dos modelos apresentados mostram que a retenção de água do solo aumentou positivamente com a densidade, pois o coeficiente f apresenta sinal positivo, o que está de acordo com os resultados obtidos por Lima et al. (2012) e Neves Junior et al. (2013) na avaliação do intervalo hídrico ótimo.

Os valores dos potenciais à capacidade de campo $(\theta \mathrm{CC})$ e do ponto de murcha permanente ( $\theta \mathrm{PMP})$ nos limites críticos de potenciais de água no solo e da resistência do solo à penetração $(\theta \mathrm{RP})$, nas duas áreas estudadas, aumentaram de acordo com a densidade do solo (Figuras 1 A e B). Resultados semelhantes foram observados por Leão et al. (2004) e Roque et al. (2011). Ressalta-se ainda que, em ambas as áreas de estudo, a

Tabela 2. Estimadores dos parâmetros de regressão linear, quanto à resistência do solo à penetração $(\mathrm{RP}, \mathrm{MPa})$, em razão do conteúdo volumétrico de água $\left(\theta=\mathrm{m}^{3} \mathrm{~m}^{-3}\right)$, e densidade do solo $\left(\mathrm{Ds}, \mathrm{Mg} \mathrm{m}^{-3}\right)$, em que $\ln \mathrm{RP}=\operatorname{lna}+\mathrm{b} \ln \theta+\mathrm{c} \operatorname{lnDs}$, e quanto ao conteúdo volumétrico de água do solo $\left(\theta=\mathrm{m}^{3} \mathrm{~m}^{-3}\right)$, em razão da densidade do solo $\left(\mathrm{Ds}=\mathrm{Mg} \mathrm{m}^{-3}\right)$ e do potencial matricial $(\mathrm{m}=\mathrm{MPa}): \ln \theta=\operatorname{lnd}+\mathrm{eDs}+\mathrm{f} \operatorname{lnm})$.

\begin{tabular}{|c|c|c|c|c|c|c|c|c|}
\hline \multirow[t]{2}{*}{ Parâmetro } & \multicolumn{4}{|c|}{ Colheita mecanizada } & \multicolumn{4}{|c|}{ Colheita manual } \\
\hline & Valor & Erro-padrão & $\mathrm{t}$ & Probabilidade $^{(1)}$ & Valor & Erro-padrão & $\mathrm{t}$ & Probabilidade $^{(1)}$ \\
\hline $\bar{a}$ & $-1,00964$ & 0,10289 & $-9,81$ & $<0,0001$ & $-1,15086$ & 0,14568 & $-7,90$ & $<0,0001$ \\
\hline $\mathrm{b}$ & $-1,18793$ & 0,06684 & $-17,77$ & $<0,0001$ & $-1,40386$ & 0,09213 & $-15,24$ & $<0,0001$ \\
\hline c & 3,09928 & 0,27025 & 11,47 & $<0,0001$ & 3,0398 & 0,29644 & 6,88 & $<0,0001$ \\
\hline d & $-2,18351$ & 0,11740 & $-19,72$ & $<0,0001$ & $-1,94175$ & 0,10884 & $-17,84$ & $<0,0001$ \\
\hline $\mathrm{e}$ & 0,37361 & 0,09092 & 4,11 & $<0,0001$ & 0,11734 & 0,08714 & 1,35 & $<0,0001$ \\
\hline$f$ & $-0,17785$ & 0,00546 & $-32,55$ & $<0,0001$ & $-0,18294$ & 0,00663 & $-27,61$ & $<0,0001$ \\
\hline
\end{tabular}

(1) Probabilidade de significância pelo teste F, para os valores estimados dos parâmetros. 
$\theta \mathrm{RP}$ foi superior ao $\theta \mathrm{PMP}$, em quase toda a extensão de valores de densidade do solo, semelhantemente aos resultados encontrados por Benjamin et al. (2003), que relacionaram o intervalo hídrico ótimo com o desempenho das culturas do trigo e do milho, e por Cavalieri et al. (2011), que estudaram o intervalo hídrico ótimo de um Latossolo Vermelho, com colheita mecanizada da cultura da cana-de-açúcar.

Para as duas áreas avaliadas, a resistência do solo à penetração foi o limite inferior do intervalo hídrico ótimo (IHO), que teve como limites superiores a $\theta \mathrm{CC}$
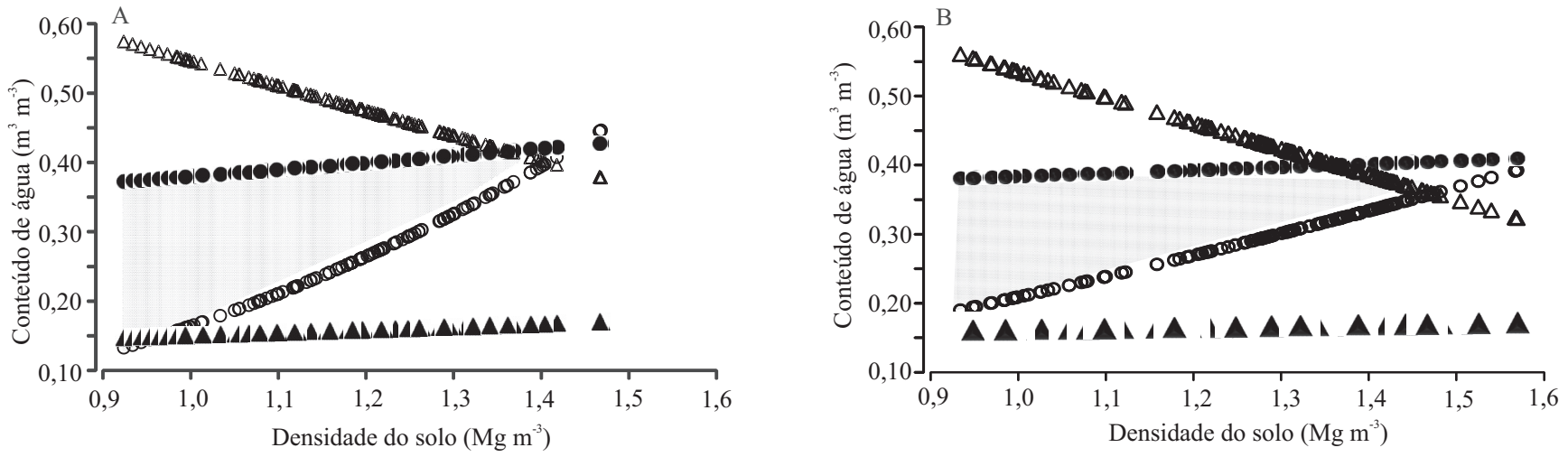

e a porosidade de aeração ( $\theta \mathrm{PA})$. Este comportamento, provavelmente, resulta do fato de que com o aumento da densidade do solo decresce a $\theta \mathrm{PA}$ a $10 \%$, o que indica também a redução dos poros de maior diâmetro (Figuras 1 A e B). Estes resultados são similares aos obtidos por Tormena et al. (2007) e Pereira et al. (2010), na determinação do IHO, em um Latossolo Vermelho distrófico.

$\mathrm{Na}$ área sob colheita mecanizada, a densidade do solo crítica, ou seja, a densidade em que o IHO é nulo, foi de $1,39 \mathrm{Mg} \mathrm{m}^{-3}$ (Figura $2 \mathrm{~A}$ ). A média da densidade do

Figura 1. Variação do conteúdo volumétrico de água $\left(\theta, \mathrm{m}^{3} \mathrm{~m}^{-3}\right)$ com a densidade do solo (Ds), para os limites críticos de capacidade de campo $(\theta \mathrm{CC}, 0,01 \mathrm{MPa})$, ponto de murcha permanente ( $\theta \mathrm{PMP}, 1,5 \mathrm{MPa})$, porosidade de aeração $(\theta \mathrm{PA}, 10 \%)$ e resistência do solo à penetração $(\theta \mathrm{RP} ; 2,5 \mathrm{MPa})$, em um Latossolo Vermelho distrófico sob colheita mecanizada $(\mathrm{A})$ e colheita manual (B), para a cultura da cana-de-açúcar, à profundidade de $0,00-0,20 \mathrm{~m}$. A área destacada representa o intervalo hídrico ótimo do solo (IHO).
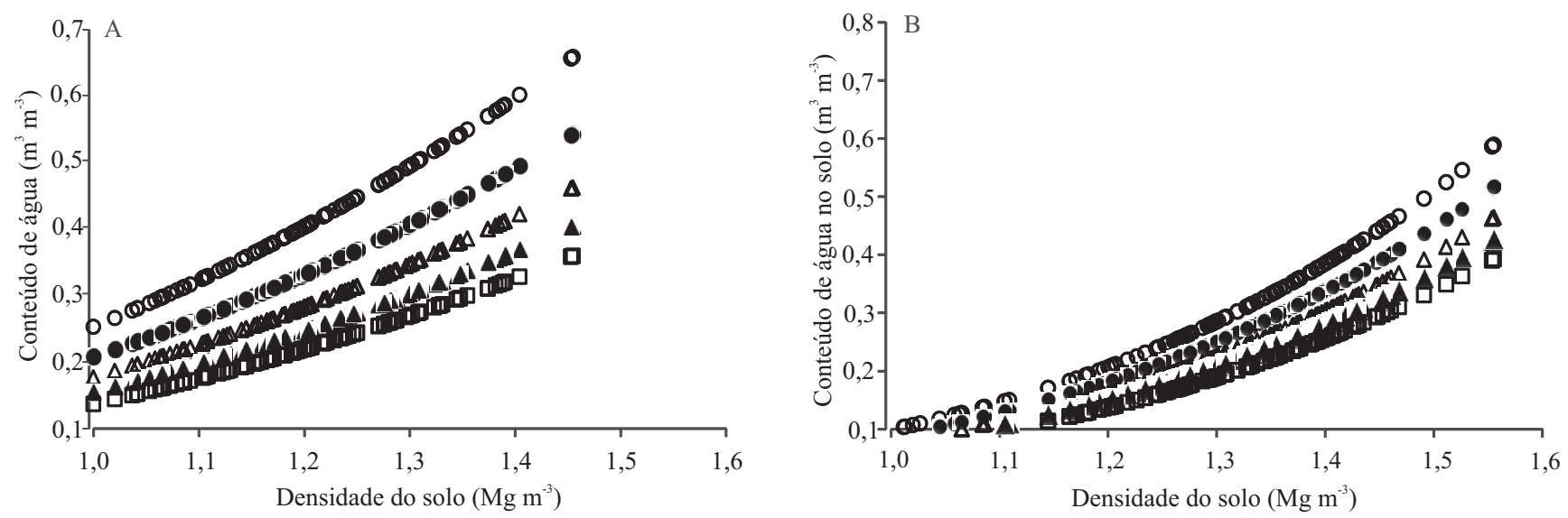

○ $\theta \mathrm{RP} 2,0 \quad \theta \mathrm{RP} 2,5 \quad \Delta \theta \mathrm{RP} 3,0 \quad \Delta \theta \mathrm{RP} 3,5 \quad \boldsymbol{\square} \theta \mathrm{RP} 4,0$

Figura 2. Variação da resistência do solo à penetração ( $\theta \mathrm{RP})$, para os limites críticos de 2,0, 2,5, 3,0, 3,5 e 4,0 MPa, com o conteúdo de água no solo e a densidade do solo, em um Latossolo Vermelho distroférrico, com colheita mecanizada (A) e colheita manual (B) da cultura da cana-de-açúcar. 
solo encontrada na área de estudo foi de $1,20 \mathrm{Mg} \mathrm{m}^{-3}$, à profundidade de $0,00-0,10 \mathrm{~m}$, e de $1,30 \mathrm{Mg} \mathrm{m}^{-3}$, às profundidades de $0,10-0,20 \mathrm{~m}$ e $0,20-0,30 \mathrm{~m}$; nessas condições, a $\theta \mathrm{RP}$ encontrou-se acima do limite crítico relatado pela literatura, que é de $2,0 \mathrm{MPa}$ (Cavalieri et al., 2011; Neves Junior et al., 2013).

$\mathrm{O}$ aumento da densidade do solo resultou em incremento dos valores de $\theta \mathrm{RP}$ (Figura $2 \mathrm{~A}$ ). Resultados semelhantes foram observados por Freddi et al. (2009), em Latossolo Vermelho distrófico típico, de textura média, sob cultivo de milho. Elevando-se o limite de $\theta \mathrm{RP}$ para 4,0 $\mathrm{MPa}$, a amplitude do IHO passaria a ser maior e proporcionaria melhores condições ao desenvolvimento das plantas. Ao estudar um Latossolo Vermelho distrófico típico, de textura argilosa, sob cultivo de cana-de-açúcar, Cavalieri et al. (2011) utilizaram o limite de 3,5 $\mathrm{MPa}$ de resistência do solo à penetração, para mensuração do IHO.

$\mathrm{Na}$ área sob colheita manual, a densidade do solo crítica foi $1,36 \mathrm{Mg} \mathrm{m}^{-3}$, e houve limitação física, pela resistência do solo à penetração $(\theta \mathrm{RP})$, para à cultura da cana-de-açúcar, com conteúdo de água entre 0,32 a $0,43 \quad \mathrm{~m}^{3} \mathrm{~m}^{-3}$ (Figura 2 B). Como a média de densidade do solo encontrada na área de estudo foi de $1,33 \mathrm{Mg} \mathrm{m}^{-3}$, à profundidade de $0,00-0,10 \mathrm{~m}$, e de $1,41 \mathrm{Mg} \mathrm{m}^{-3}$, à profundidade de $0,10-0,20 \mathrm{~m}$, a $\theta \mathrm{RP}$ encontra-se acima do limite crítico relatado pela literatura que é de 2,0 MPa (Collares et al., 2006; Neves Junior et al., 2013).

Quanto a variabilidade espacial, observou-se dependência espacial para produtividade, em todas as áreas estudadas, e o modelo que melhor se ajustou aos semivariogramas experimentais foi o esférico, exceto para a área com colheita manual, para a qual o modelo que melhor se ajustou aos dados foi o exponencial (Tabela 3). Ao estudar a dependência espacial de atributos de planta, em áreas sob cultivo de cana-de-açúcar, Souza et al. (2010) também encontraram ajuste ao modelo esférico para a produtividade.

Verifica-se predomínio de manchas nítidas com os maiores valores de produção observados nas regiões de maior cota da área (Figura 3). Resultados semelhantes foram observados por Souza et al. (2010), na correlação positiva da altitude do terreno com a produtividade, o que indica que, nas áreas menos elevadas do talhão, a produtividade é menor. Ceddia et al. (2009) estudaram a relação da topografia com atributos físicos do solo e observaram que, em cotas mais elevadas do terreno, os teores de argila e a retenção de água são maiores, o que pode favorecer o desenvolvimento das culturas agrícolas.

Cruzando-se os dados dos limites críticos das áreas com os mapas de produtividade das culturas, observase que houve maior restrição na área com colheita manual, que apresentou menor densidade crítica $\left(1,36 \mathrm{Mg} \mathrm{m}^{-3}\right)$; isto pode ter causado restrições hídricas, durante o manejo, e a diminuição da produtividade da cultura, que foi de $124,04 \mathrm{Mg} \mathrm{ha}^{-1}$ na área com corte manual (Figura 3). Tasso Júnior (2007) avaliaram o desempenho agrotecnológico de cultivares de cana-de-açúcar e obtiveram produtividade média de $165,55 \mathrm{Mg} \mathrm{ha}^{-1}$, na região centro-norte do Estado de São Paulo. Na área com colheita mecanizada, a maior densidade crítica do solo $\left(1,39 \mathrm{Mg} \mathrm{m}^{-3}\right)$ favoreceu a permanência de condições ideais de manejo, ao longo do ciclo da cultura, o que se refletiu na obtenção de maiores valores de produtividade para esta área, que obteve o valor médio de produtividade de 144,78 $\mathrm{Mg} \mathrm{ha}^{-1}$. Quanto maior densidade do solo a

Tabela 3. Modelos e parâmetros, estimados dos semivariogramas experimentais para a produtividade da cultura de cana-deaçúcar, para área com colheita mecanizada (14 anos) e colheita manual (20 anos).

\begin{tabular}{|c|c|c|c|c|c|c|}
\hline \multirow[t]{2}{*}{ Parâmetro } & \multicolumn{2}{|c|}{ Produtividade $\left(\mathrm{Mg} \mathrm{ha}^{-1}\right)$} & \multicolumn{2}{|c|}{ Densidade $\left(\mathrm{Mg} \mathrm{m}^{-3}\right)$} & \multicolumn{2}{|c|}{ Água disponível $\left(\mathrm{m}^{3} \mathrm{~m}^{-3}\right)$} \\
\hline & Mecanizada & Manual & Mecanizada & Manual & Mecanizada & Manual \\
\hline Modelo & Esférico & Exponencial & Esférico & Esférico & Esférico & Esférico \\
\hline $\mathrm{C}_{0}$ & 1,000 & 298,0 & 0,00258 & 0,00174 & 0,00054 & 0,00000 \\
\hline $\mathrm{C}_{0}+\mathrm{C}_{1}$ & 797,40 & 955,50 & 0,01106 & 0,00762 & 0,00257 & 0,00055 \\
\hline $\mathrm{a}(\mathrm{m})$ & 24,100 & 73,20 & 17,2 & 16,7 & 16,20 & 27,50 \\
\hline GDE (\%) & 99,87 & 68,81 & 23.33 & 22.83 & 21.01 & 0,0 \\
\hline $\mathrm{R}^{2}(\%)$ & 79,0 & 87,70 & 97,50 & 88,0 & 71,7 & 66,6 \\
\hline SQR & 61992 & 31202 & $1,028^{\mathrm{E}-07}$ & $3,080^{\mathrm{E}-07}$ & $6,883^{\mathrm{E}-08}$ & $6,732^{\mathrm{E}-08}$ \\
\hline
\end{tabular}

$\mathrm{C}_{0}$, efeito pepita; $\mathrm{C}_{0}+\mathrm{C}_{1}$, patamar; a, alcance; GDE, grau de dependência espacial; $\mathrm{R}^{2}$, coeficiente de determinação do modelo; $\mathrm{SQR}$, soma de quadrados do resíduo. 

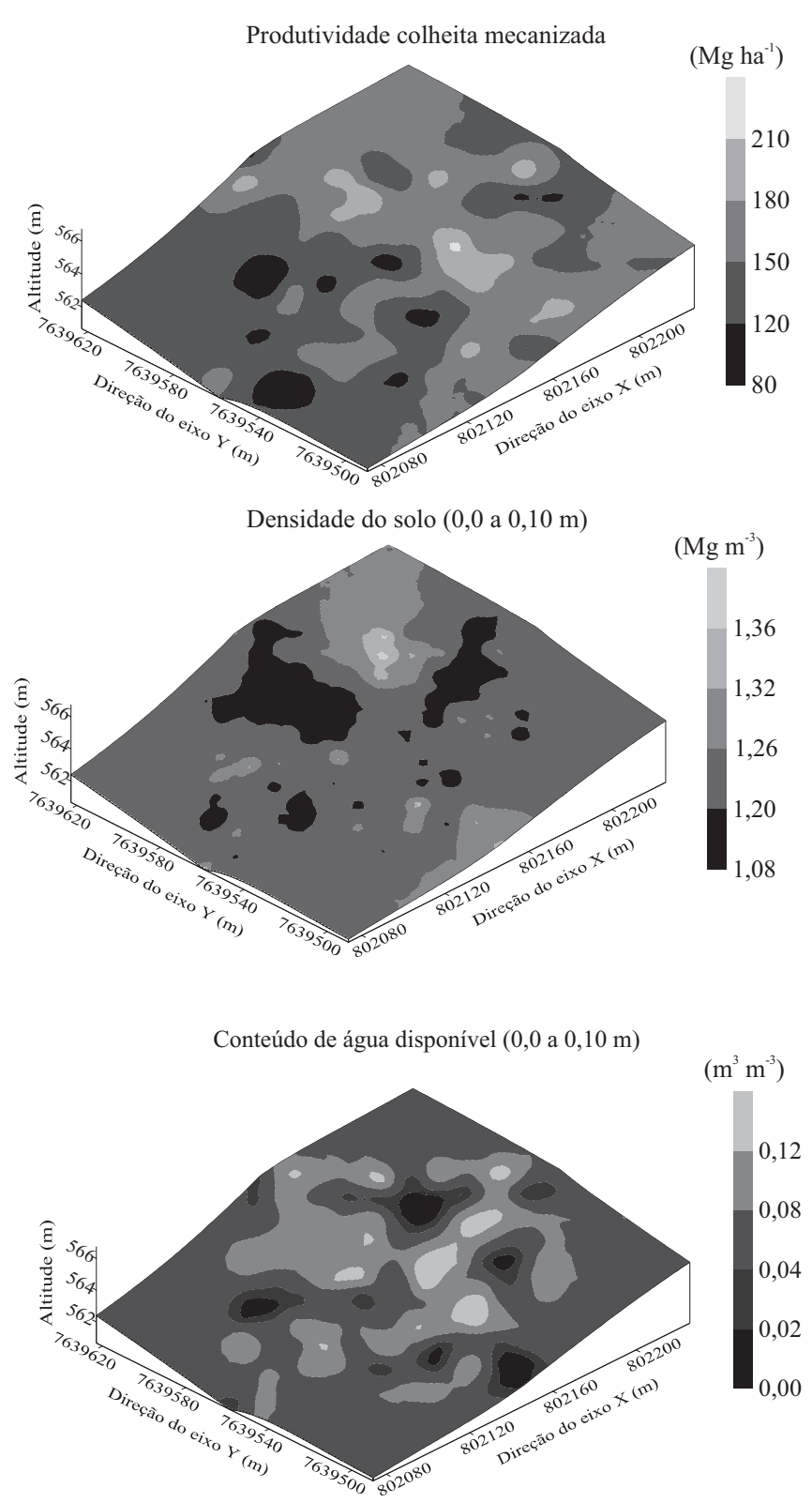

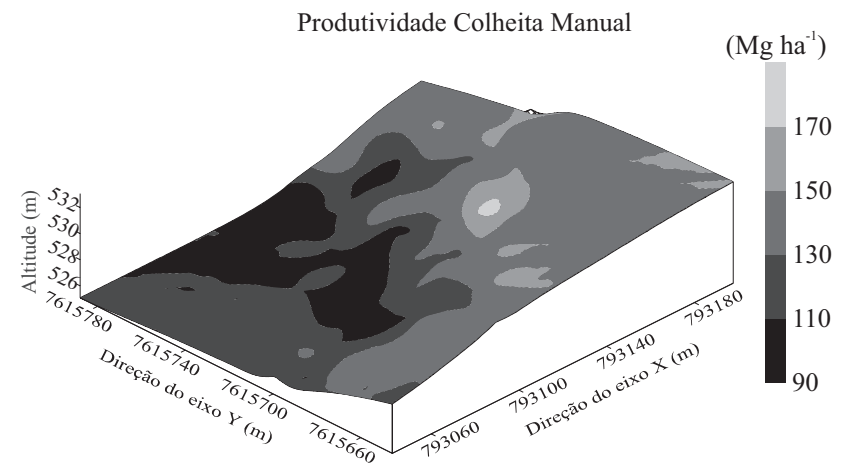

Densidade do solo $(0,0$ a $0,10 \mathrm{~m})$

$\left(\mathrm{Mg} \mathrm{m}^{-3}\right)$

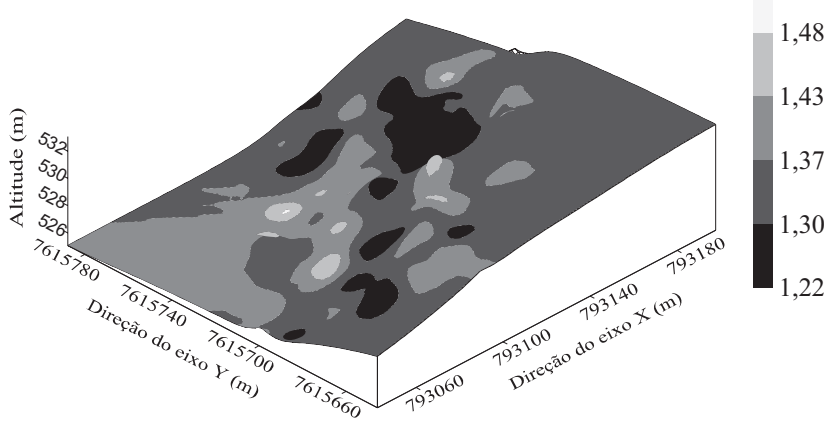

Conteúdo de água disponível $(0,0$ a $0,10 \mathrm{~m})$

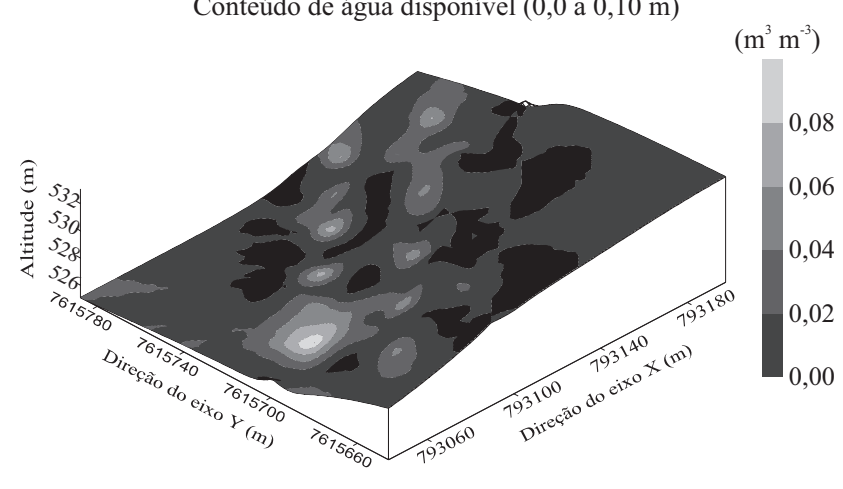

Figura 3. Distribuição espacial da produtividade da cultura de cana de açúcar, da densidade do solo e conteúdo de água disponível estimado pelo intervalo hídrico ótimo, para as áreas com colheita mecanizada e manual.

cultura agrícola suportar, maior será a faixa em que o conteúdo de água do solo não representa impedimento físico para o seu desenvolvimento. Leão et al. (2004) observaram densidade crítica de $1,46 \mathrm{Mg} \mathrm{m}^{-3}$, com RP de 3,0 MPa, em um Latossolo Vermelho distrófico de textura argilosa. Souza et al. (2005) estudaram sistemas de colheita e manejo da palhada de cana-de-açúcar e verificaram maior produtividade nas áreas com colheita mecanizada (cana crua).

\section{Conclusões}

1. O intervalo hídrico ótimo é afetado pelos dois sistemas de colheita da cana-de-açúcar avaliados e mostra maior degradação estrutural do solo e menor conteúdo de água disponível na área de colheita manual.

2. A área de colheita manual da cana-de-açúcar apresenta menor valor de densidade crítica para o intervalo hídrico ótimo. 
3. A maior produtividade da cana-de-açúcar concentra-se nas regiões de maior amplitude do intervalo hídrico ótimo.

\section{Agradecimentos}

À Coordenação de Aperfeiçoamento de Pessoal de Nível Superior (Capes), por concessão de bolsa; à Fundação de Amparo à Pesquisa do Estado de São Paulo (Fapesp), pelo financiamento do projeto; e à Usina São Martinho, por disponibilizar a área de estudo.

\section{Referências}

BENJAMIN, J.G.; NIELSEN, D.C.; VIGIL, M.F. Quantifying effects of soil conditions on plant growth and crop production. Geoderma, v.116, p.137-148, 2003. DOI: 10.1016/ S0016-7061(03)00098-3.

BETIOLI JÚNIOR, E.; MOREIRA, W.H.; TORMENA, C.A.; FERREIRA, C.J.B.; SILVA, A.P. da; GIAROLA, N.F.B. Intervalo hídrico ótimo e grau de compactação de um Latossolo Vermelho após 30 anos sob plantio direto. Revista Brasileira de Ciência do Solo, v.36, p.971-982, 2012. DOI: 10.1590/ S0100-06832012000300027.

BERNER, P.G.M.; VIEIRA, S.R.; LIMA, E.; ANJOS, L.H.C. dos. Variabilidade espacial de propriedades físicas e químicas de um Cambissolo sob dois sistemas de manejo de cana-de-açúcar. Revista Brasileira de Ciência do Solo, v.31, p.837-844, 2007. DOI: 10.1590/S0100-06832007000500001.

BRAIDA, J.A.; REICHERT, J.M.; VEIGA, M. da; REINERT, D.J. Resíduos vegetais na superfície e carbono orgânico do solo e suas relações com a densidade máxima obtida no ensaio Proctor. Revista Brasileira de Ciência do Solo, v.30, p.605-614, 2006. DOI: $10.1590 / \mathrm{S} 0100-06832006000400001$.

CAVALIERI, K.M.V.; CARVALHO, L.A. de; SILVA, A.P. da; LIBARDI, P.L.; TORMENA, C.A. Qualidade física de três solos sob colheita mecanizada de cana-de-açúcar. Revista Brasileira de Ciência do Solo, v.35, p.1541-1549, 2011. DOI: 10.1590/ S0100-06832011000500008.

CEDDIA, M.B.; VIEIRA, S.R.; VILLELA, A.L.O.; MOTA, L. dos S.; ANJOS, L.H.C. dos; CARVALHO, D.F. de. Topografia e variabilidade espacial de propriedades físicas do solo. Scientia Agricola, v.66, p.338-352, 2009. DOI: 10.1590/ S0103-90162009000300009.

CENTRO DE PESQUISAS METEOROLÓGICAS E CLIMÁTICAS APLICADAS À AGRICULTURA. Clima dos municípios paulistas. 2013. Disponível em: <http://www.cpa. unicamp.br/outras-informacoes/clima_muni_461.html>. Acesso em: 26 jul. 2013.

COLLARES, G.L.; REINERT, D.J.; REICHERT, J.M.; KAISER, D.R. Qualidade física do solo na produtividade da cultura do feijoeiro num Argissolo. Pesquisa Agropecuária Brasileira, v.41, p.1663-1674, 2006. DOI: 10.1590/S0100-204X2006001100013.

DEXTER, A.R. Soil physical quality. Part I. Theory, effects of soil texture, density, and organic matter, and effects on root growth. Geoderma, v.120, p.201-214, 2004. DOI: 10.1016/j. geoderma.2003.09.004.

DONAGEMA, G.K.; CAMPOS, D.V.B. de; CALDERANO, S.B.; TEIXEIRA, W.G.; VIANA, J.H.M. (Org.). Manual de métodos de análise de solos. 2.ed. rev. Rio de Janeiro: Embrapa Solos, 2011. 230p. (Embrapa Solos. Documentos, 132).

FREDDI, O. da S.; CENTURION, J.F.; DUARTE, A.P.; PERES, F.S.C. Compactação do solo e produção de cultivares de milho em Latossolo Vermelho. II - Intervalo hídrico ótimo e sistema radicular. Revista Brasileira de Ciência do Solo, v.33, p.805-818, 2009. DOI: $10.1590 / \mathrm{S} 0100-06832009000400006$

GARBIATE, M.V.; VITORINO, A.C.T.; TOMASINI, B.A.; BERGAMIN, A.C.; PANACHUKI, E. Erosão entre sulcos em área cultivada com cana crua e queimada sob colheita manual e mecanizada. Revista Brasileira de Ciência do Solo, v.35, p.2145-2155, 2011. DOI: 10.1590/S0100-06832011000600029.

LAPEN, D.R.; TOPP, G.C.; GREGORICH, E.G.; CURNOE, W.E. Least limiting water range indicators of soil quality and corn production, Eastern Ontario, Canada. Soil and Tillage Research, v.78, p.151-170, 2004. DOI: 10.1016/j.still.2004.02.004.

LEÃO, T.P.; SILVA, A.P.; MACEDO, M.C.M.; IMHOFF, S.C.; EUCLIDES, V.P.B. Intervalo hídrico ótimo na avaliação de sistemas de pastejo contínuo e rotacionado. Revista Brasileira de Ciência do Solo, v.28, p.415-423, 2004. DOI: 10.1590/ S0100-06832004000300002.

LETEY, J. Relationship between soil physical properties and crop production. Advances in Soil Science, v.1, p.277-294, 1985. DOI: 10.1007/978-1-4612-5046-3 8.

LIMA, V.M.P.; OLIVEIRA, G.C. de; SERAFIM, M.E.; CURI, N.; EVANGELISTA, A.R. Intervalo hídrico ótimo como indicador de melhoria da qualidade estrutural de latossolo degradado. Revista Brasileira de Ciência do Solo, v.36, p.71-78, 2012. DOI: 10.1590/ S0100-06832012000100008.

NEVES JUNIOR, A.F.; SILVA, A.P. da; NORONHA, N.C.; CERRI, C.C. Sistemas de manejo do solo na recuperação de uma pastagem degradada em Rondônia. Revista Brasileira de Ciência do Solo, v.37, p.232-241, 2013. DOI: 10.1590/ S0100-06832013000100024.

PACHECO, E.P.; CANTALICE, J.R.B. Compressibilidade, resistência à penetração e intervalo hídrico ótimo de um Argissolo Amarelo cultivado com cana-de-açúcar nos Tabuleiros Costeiros de Alagoas. Revista Brasileira de Ciência do Solo, v.35, p.403-415, 2011. DOI: 10.1590/S0100-06832011000200010.

PEREIRA, F. de S.; ANDRIOLI, I.; BEUTLER A.N.; ALMEIDA, C.X. de; PEREIRA, F. de S. Physical quality of an Oxisol cultivated with maize submitted to cover crops in the pre-cropping period. Revista Brasileira de Ciência do Solo, v.34, p.211-217, 2010. DOI: $10.1590 /$ S0100-06832010000100021.

ROQUE, A.A. de O.; SOUZA, Z.M.; ARAÚJO, F.S.; SILVA, G.R.V. da. Atributos físicos do solo e intervalo hídrico ótimo de um Latossolo Vermelho distrófico sob controle de tráfego 
agrícola. Ciência Rural, v.41, p.1536-1542, 2011. DOI: 10.1590/ S0103-84782011005000117.

SANTOS, H.G. dos; JACOMINE, P.K.T.; ANJOS, L.H.C. dos; OLIVEIRA, V.A. de; OLIVEIRA, J.B. de; COELHO, M.R.; LUMBRERAS, J.F.; CUNHA, T.J.F. (Ed.). Sistema brasileiro de classificação de solos. 2.ed. Rio de janeiro: Embrapa Solos, 2006. $306 \mathrm{p}$

SILVA, A.P. da; KAY, B.D.; PERFECT, E. Characterization of the least limiting water range of soils. Soil Science Society of America Journal, v.58, p.1775-1781, 1994. DOI: 10.2136/sssaj1994.03615 995005800060028x.

SOUZA, G.S. de; SOUZA, Z.M. de; SILVA, R.B. da; ARAUJO, F.S.; BARBOSA, R.S. Compressibilidade do solo e sistema radicular da cana-de-açúcar em manejo com e sem controle de tráfego. Pesquisa Agropecuária Brasileira, v.47, p.603-612, 2012. DOI: $10.1590 / \mathrm{S} 0100-204 X 2012000400017$

SOUZA, Z.M. de; CERRI, D.G.P.; COLET, M.J.; RODRIGUES, L.H.A.; MAGALHÃES, P.S.G.; MANDONI, R.J.A. Análise dos atributos do solo e da produtividade da cultura de cana-de-açúcar com o uso da geoestatística e árvore de decisão. Ciência Rural, v.40, p.840-847, 2010. DOI: 10.1590/ S0103-84782010005000048.

SOUZA, Z.M. de; MARQUES JUNIOR, J.; PEREIRA, G.T.; SÁENZ, C.M.S. Spatial variability of aggregate stability in Latosols under sugarcane. Revista Brasileira de Ciência do Solo, v.33, p.245-254, 2009. DOI: 10.1590/S0100-06832009000200002.

SOUZA, Z.M. de; PRADO, R. de M.; PAIXÃO, A.C.S.; CESARIN, L.G. Sistemas de colheita e manejo da palhada de cana-de-açúcar. Pesquisa Agropecuária Brasileira, v.40, p.271-278, 2005. DOI: 10.1590/S0100-204X2005000300011.

TASSO JÚNIOR, L.C. Caracterização agrotecnológica de cultivares de cana-de-açúcar (Saccharum spp.) na região centro-norte do estado de São Paulo. 2007. 167p. Tese (Doutorado) - Universidade Estadual Paulista, Jaboticabal.

TORMENA, C.A.; ARAÚJO, M.A.; FIDALSKI, J.; COSTA, J.M. da. Variação temporal do intervalo hídrico ótimo de um Latossolo Vermelho distroférrico sob sistemas de plantio direto. Revista Brasileira de Ciência do Solo, v.31, p.211-219, 2007. DOI: 10.1590/S0100-06832007000200003.

TORMENA, C.A.; SILVA, A.P.; LIBARDI, P. Caracterização do intervalo hídrico ótimo de um Latossolo Roxo sob plantio direto. Revista Brasileira de Ciência do Solo, v.22, p.573-581, 1998.

VASCONCELOS, R.F.B.; CANTALICE, J.R.B.; MOURA, G.B.A.; ROLIM, M.M.; MONTENEGRO, C.E.V. Compressibilidade de um Latossolo Amarelo distrocoeso não saturado sob diferentes sistemas de manejo da cana-de-açúcar. Revista Brasileira de Ciência do Solo, v.36, p.525-536, 2012. DOI: 10.1590/ S0100-06832012000200022.

VIEIRA, S.R. Geoestatística em estudos de variabilidade espacial do solo. In: NOVAIS, R.F. de; ALVAREZ V., V.H.; SCHAEFER, C.E.G.R. (Ed.). Tópicos em ciência do solo. Viçosa: Sociedade Brasileira de Ciência do Solo, 2000. p.1-54.

WARRICK, A.W.; NIELSEN, D.R. Spatial variability of soil physical properties in the field. In: HILLEL, D. (Ed.). Applications of soil physics. New York: Academic, 1980. p.319-344.

Recebido em 22 de fevereiro de 2013 e aprovado em 29 de maio de 2013 